\title{
AS RELAÇÕES SOCIAIS E ECONÔMICAS E SEUS REFLEXOS NA PAISAGEM CULTURAL URBANA DE SANTA MARIA, RS: CONSIDERAÇÕES TEÓRICAS ${ }^{1}$
}

\author{
SOCIAL AND ECONOMIC RELATIONS AND ITS REFLECTIONS IN \\ THE URBAN CULTURAL LANDSCAPE OF SANTA MARIA, RS: \\ THEORETICAL CONSIDERATIONS
}

\author{
Andrei Wahlbrink², Maurício Rizzatti ${ }^{3}$, \\ Pedro Leonardo Cezar Spode ${ }^{4}$ e Natália Lampert Batista ${ }^{5}$
}

\section{RESUMO}

Este trabalho tem como objetivo apresentar discussão a respeito dos elementos econômicos e sociais, que influenciaram na construção da paisagem cultural urbana de Santa Maria, RS. Para isso, foram utilizados referencial bibliográfico que auxilia na compreensão da formação socioeconômica da cidade, com trabalhos como o de Padoin (1992) e Beber (1998), como também, a utilização de fotografias históricas e atuais, que demonstram a evolução das formas construídas em Santa Maria. As imagens foram coletadas em sites especializados, principalmente, o site do Acervo Histórico Municipal de Santa Maria, além de imagens do Google Imagens e entre outros. Concluímos que a formação histórica e geográfica de Santa Maria, possui influência do modelo político e econômico praticado no Brasil e no Rio Grande do Sul durante o processo histórico, cujo reflexo se dá sobre as formas construídas na cidade, que atuam como signos, marcas e registros de outros períodos, no espaço geográfico do município.

Palavras-chave: Geografia Cultural. Materialidade das paisagens. Memória. Patrimônio.

\section{ABSTRACT}

This work aims to present a discussion about the economic and social elements that influenced the construction of the urban cultural landscape of Santa Maria, RS. For this purpose, a bibliographic reference was used to help on the understanding of the socioeconomic formation of the city, with works such as that of Padoin (1992) and Beber (1998), as well as the use of historical and current photographs, which demonstrate the evolution of the constructed forms in Santa Maria. The images were collected on specialized sites, mainly the site of the Acervo Histórico Municipal de Santa Maria, as well as images from Google Earth and others. We conclude that the historical and geographical formation of Santa Maria, has influence of the political and economic model practiced in Brazil and Rio Grande do Sul during the historical process, whose reflection is given on the forms constructed in the city, which act as signs, marks and records from other periods, in the geographical space of the municipality.

Keywords: Cultural Geography. Materiality of landscapes. Memory. Patrimony.

\footnotetext{
${ }^{1}$ Trabalho de Pesquisa.

${ }^{2}$ Bacharel em Ciências Sociais - Universidade Federal de Santa Maria. E-mail: andreyvahlbrink@yahoo.com.br

${ }_{3}^{3}$ Doutorando em Geografia - Universidade Federal de Santa Maria. E-mail: geo.mauricio.rizzatti@gmail.com

${ }^{4}$ Doutorando em Geografia - Universidade Federal de Santa Maria. E-mail: pedrospode@gmail.com

${ }^{5}$ Pós-doutoranda em Geografia - Universidade Federal de Santa Maria. E-mail: natilbatista3@gmail.com
} 


\section{INTRODUÇÃO}

Este trabalho tem como objetivo apresentar discussão a respeito dos elementos econômicos e sociais, que influenciaram na construção da paisagem cultural urbana de Santa Maria, RS. Para isso, foram utilizados referencial bibliográfico que auxilia na compreensão da formação socioeconômica da cidade, com trabalhos como o de Padoin (1992) e Beber (1998), como também, a utilização de fotografias históricas e atuais, que demonstram a evolução das formas construídas em Santa Maria. As imagens foram coletadas em sites especializados, principalmente, o site do Acervo Histórico Municipal de Santa Maria, além de imagens do Google Imagens e entre outros.

A abordagem do artigo vincula-se diretamente com a Geografia Cultural, que segundo Claval (2002, p. 19), “[...] nasceu na mesma época da Geografia Humana, no final do século dezenove”. O objetivo da abordagem cultural, segundo o autor, é entender a experiência dos humanos no ambiente, entender a significação que o humano impõe a esse ambiente e o sentido dado às suas vidas frente a essa interpretação. A abordagem cultural integra as representações mentais e as reações subjetivas no campo da pesquisa geográfica, potencializando o entendimento do urbano em essência e o desenvolvimento do sentimento de pertença (CLAVAL, 2002).

Essa abordagem se associa também as noções de patrimônio cultural:

O patrimônio histórico cultural materializa e torna visível esse sentimento evocado pela cultura e pela memória e, assim, permite a construção das identidades coletivas, fortalecendo os elos das origens comuns, passo decisivo para a continuidade e a sobrevivência de uma comunidade. Além desse aspecto de construção de identidade, a noção de patrimônio cultural diz respeito à herança coletiva que deve ser transmitida às futuras gerações, de forma a relacionar o passado e o presente, permitindo a visão do futuro, segundo as Diretrizes para Proteção do Patrimônio Cultural. [...] A preservação do patrimônio cultural visa à continuidade das manifestações culturais, promove a melhoria da qualidade de vida da comunidade, implica na manutenção de seu bem estar material e espiritual e garante o exercício da cidadania. (FIGUEIREDO, 2013, p. 59)

Nesse sentido, o presente trabalho contribui significativamente na recuperação e preservação da memória santa-mariense, prestando-se como uma fonte de investigação cultural e urbana e com vistas a preservação do patrimônio histórico local pelo resgate da memória coletiva do lugar. Tem como centralidade a reconstrução e a valorização do passado urbano de Santa Maria, como fonte de compreensão da realidade contemporânea, por meio da intervenção teórico-conceitual sobre o que constituiu e ainda se constitui a cidade.

Reconstituir a memória de um determinado lugar não significa apenas valorizar as lembranças mortas ou individuais através de textos, imagens ou espetáculos teatrais como sempre foi feito e inclusive permanece até hoje. Significa então, intervir nas ações de determinados sujeitos sociais, substituindo a fútil ocupação intensiva pela preservação dos espaços que ainda representam uma identidade, valorizando a memória urbana da coletividade e deixando-a viva, num processo cuja lógica de mercado necessite do real valor de uso dessa obra. (FIGUEIREDO, 2013, p. 66). 
A discussão desse trabalho se organiza em dois momentos: o primeiro realizando breve discussão histórica, a respeito dos contextos socioeconômicos do Brasil e de Santa Maria, em meados do final do século XIX e a metade do século XX; e o segundo, adentrando mais especificamente na constituição da paisagem urbana da cidade, apresentando fotografias que auxiliam na compreensão dessa temática e remetem ao patrimônio cultural local.

\section{TRAJETÓRIAS HISTÓRICAS DE SANTA MARIA}

Chama atenção na paisagem de Santa Maria os morros cobertos por mata atlântica que limitam toda a extensão do lado norte, e na direção leste da cidade, na direção da capital do estado (Porto Alegre), um extenso vale coberto pelo pampa, onde se verifica em grandes partes plantações de arroz que indicam os limites da cidade. Entretanto, é no centro da cidade que se encontra a concentração urbana, com grande tráfego de pessoas e automóveis, comércios e serviços de diversas ordens.

A paisagem dinâmica toma o espaço diante de nossos olhos, e o espaço que ela ocupa abrange diversas formas arquitetônicas que simbolizam e compõem relações sociais. Essas formas arquitetônicas são registros e marcas de uma materialidade histórica que revelam relações sociais de diferentes períodos e registros históricos que se tornam signos de relações sociais extintas, prestes a se extinguir, além das relações sociais que insistem em se manter (COSGROVE, 1998).

Cabe evidenciar que é praticamente impossível estudar todo o patrimônio arquitetônico e paisagístico de Santa Maria, por essa razão, esse estudo se deterá na forma arquitetônica que se configuram em intermediações com as relações sociais cotidianas mais expressivas no sentido quantitativo da cidade no presente, e também aquelas que estão no imaginário popular, imortalizadas em mitos como o aparato ferroviário e a Vila Belga, que estão mais a representar um passado que foi quase completamente esquecido e relações sociais que foram extintas. Contudo, antes de iniciar essa discussão, torna-se fundamental definir com mais clareza o que se entende por paisagem, utilizando o campo da geografia para compreensão desse conceito.

Segundo Cosgrove (1998. p. 99), a paisagem é: “ (i) um foco nas formas visíveis do nosso mundo, sua composição e estrutura espacial; (ii) unidade coerência e ordem ou concepção racional do meio ambiente; (iii) a ideia de intervenção humana e controle das forças que modelam e remodelam nosso mundo".

Existem diversas relações que se estabelecem sobre o espaço, seguindo o mesmo autor, no mesmo espaço da cidade onde seria ou é destinado ao comércio, percebe-se uma gama de relações que se interpõem no cotidiano, como os jovens universitários de cabelo colorido que pedem dinheiro aos motoristas no semáforo, ou mesmo indígenas vendendo artesanatos e ervas em bancas na calçada. A paisagem humana é detentora de relações distintas que se interpõem. De outro modo, Cosgrove (1998) refere-se a cultura como poder para compreender de que modo se dá a codificação das paisa- 
gens simbólicas: "poderíamos falar de culturas dominantes, residuais, emergentes e excluídas, cada uma das quais terá um impacto diferente sobre a paisagem humana" (COSGROVE, 1998. p. 111).

Cosgrove (1998) tipifica três formas de cultura, mas nos deteremos no momento a cultura dominante:

\begin{abstract}
Quando falo em poder não quero me referir apenas no sentido limitado de um grupo executivo ou de governo em particular, mais precisamente ao grupo ou classe cuja a dominação sobre outros está baseada objetivamente no controle dos meios de vida: terra, capital, matérias-primas e força de trabalho. No final são eles que determinam, de acordo com seus próprios valores, a locação do excedente social produzido por toda a comunidade. Seu poder é mantido e reproduzido, até um ponto considerado realmente importante, por sua capacidade de projetar e comunicar [...] através de todos os outros níveis e divisões sociais, uma imagem do mundo consoante com sua própria experiência e ter esta imagem aceita como reflexo verdadeiro da realidade de cada um (COSGROVE 1998, p. 111-112).
\end{abstract}

Toda este desenrolar teórico tem como meta compreender a conjuntura histórica e política que deram a "forma" as paisagens que modelam o espaço de Santa Maria e como isso traçar um perfil sintético a posteriori das relações de força dos grupos dominantes e sua cultura que influenciam a socialização Santa-Mariense.

Após este trabalho é possível compreender a dinâmica das contradições que se inserem e dão forma a este espaço. Semelhantes acontecimentos na Europa com os Estados Nacionais, também ocorreram no Estado Brasileiro, que passou a partir de 1930 a inaugurar o seu insulamento burocrático de um Estado Moderno através de um pacto de classes na forma de um Estado Corporativista. Cabe ressaltar como esse processo impactou Santa Maria e como isso deu forma ao objeto desta pesquisa.

Para auxiliar nessa discussão, utilizamos o trabalho de Padoin (1992), que realizou um estudo sobre o perfil dos empresários de Santa Maria. A autora faz um resgate histórico da origem da cidade, passando pela formação de pequenas cidades no seu entorno, pelo processo de imigração alemã e italiana, a implementação dos ramais ferroviários, os primeiros comércios e indústrias, como também, a organização da classe empresarial até os dias mais recentes. Ela compara os discursos dos empresários de Santa Maria com o que tange a problematização da teoria de Schumpeter ${ }^{6}$ sobre o "ato inovador". Tal problematização remete ao "Empresário Inovador”, que seria o responsável por mudanças contínuas nas forças produtivas através de mecanismos no sistema de destruições criativas. A inovação provocaria sucessivas mudanças do sistema capitalista com ciclos, de períodos de prosperidade e períodos de recessão.

Nesta comparação, Padoin (1992) chega à conclusão que a classe empresarial de Santa Maria não se encaixa perfeitamente no enquadramento teórico de "empresários inovadores", pois segundo a autora, o projeto de industrialização considerado como um ato inovador esbarrou no período de recessão após o período do "milagre brasileiro" e pela "mentalidade" do empresariado local. Quanto a este

${ }^{6}$ Teoria encontrada na obra original: Schumpeter J. A. (1939), Business Cycles. New York, NY: McGraw-Hill. 
estudo, cabe destacar alguns dados que ajudarão no entendimento da cultura local que de certa maneira influenciaram na construção e desenvolvimento do espaço e da paisagem urbana de Santa Maria.

O primeiro dado diz respeito da importância da construção das estradas de ferro ou da malha ferroviária que envolvia o estado do Rio Grande do Sul (RS), no final do Império e até o período da presidência de Juscelino Kubitschek. A malha ferroviária no RS proporcionou o nascimento das primeiras indústrias gaúchas no final do Império e durante a República Velha. Consta, segundo Padoin (1992), que o ano de 1885 fora o marco inaugural das estradas de ferro em Santa Maria, que possibilitava a sua ligação com a capital do Estado.

O segundo dado importante menciona que em 1897 a classe empresarial de Santa Maria funda uma associação de classe chamada Praça do Comércio, que tinha o objetivo de proteger-se do contrabando de produtos e comércio ilegal, ao mesmo tempo em que o comércio legal pagava altas taxas de impostos. Em 1918, a Praça do Comércio passou a se chamar Associação Comercial de Santa Maria e, em 1976, houve uma nova alteração para Câmara de Comércio e Indústria de Santa Maria (CACISM).

O terceiro ponto diz respeito ao desenvolvimento e consolidação de um grande aparato de funcionalismo público. Desde os primórdios da fundação de Santa Maria havia larga presença militar, diversas escolas e, posteriormente, universidades que deram a cidade um expressivo contingente de funcionários públicos e demandantes de serviços. O último dado importante remete a acontecimentos triplos de via única, como a queda dos preços do gado gaúcho, que proporcionava um excedente que era investido nas indústrias, acompanhado pela maior centralização do poder do Governo Federal em 1930, tendo como plano o status para o estado do Rio Grande do Sul de "Celeiro" do Brasil.

O terceiro acontecimento de via única menciona a passagem da administração das vias férreas do estado do Rio Grande do Sul para o Governo Federal. Todos estes dados merecem um melhor desenvolvimento. A importância da construção das linhas férreas vai muito além do aumento da renda municipal de 523\% num período de 15 anos (PADOIN, 1992). A sua importância se deve a construção e ampliação disseminada pelo estado do Rio Grande do Sul da categoria de "solidariedade orgânica" de Durkheim ${ }^{7}$. Considerando o aumento da produção industrial e a experiência de classe vivida pela população em geral, mais precisamente pela classe trabalhadora, pode-se perceber uma sociedade de ampla coesão social, com suas classes e diversas frações de classes intermediárias, que tornavam isso possível pela divisão social do trabalho em constante ampliação, especialização e racionalização. A racionalização é necessária no plano jurídico para resolução de conflitos que as desigualdades econômicas entre as classes ocasionavam.

Conforme Petersen e Lucas (1992), os primeiros movimentos sindicais no Rio Grande do Sul não tiveram uma orientação socialista, embora fossem intuitivamente revolucionários e se confundiam com o movimento abolicionista e republicano. Não demorou muito para que imigrantes alemães

\footnotetext{
${ }^{7}$ Ver Durkheim, "Da divisão Social do Trabalho" - conceito de solidariedade orgânica.
} 
vindos ao RS para servir de mão de obra nas indústrias, trouxessem consigo a influência do Partido Social Democrata Alemão. A social democracia logo ganharia maior respaldo no Partido Republicano Rio-Grandense (PRR), com a candidatura do líder sindical Francisco Xavier da Costa, em 1912. Este mesmo líder sindical fora um dos primeiros negociantes grevistas durante as construções das linhas férreas gaúchas. Petersen e Lucas (1992) mencionam que anarquistas e socialistas dividiam os mesmos espaços nas organizações sindicais e de classe. Entre 1906 e 1907 os anarquistas e socialistas possuíam certas concordâncias, entre estas a manutenção da neutralidade política por parte das sociedades de resistência, como associações de classe e sindicatos, embora houvesse certa tendência de que qualquer associação de classe fosse absorvida pelo PRR ou pelos federalistas. Sendo assim, tal posicionamento não impedia que certos grupos aderissem ao engajamento político. Pode-se perceber com isso que o aumento da industrialização no RS ao mesmo tempo em que gerava conflitos de classe, também gerava espaços de intermediações, sendo em associações ou ainda em negociações de conflitos. Em 1906 foi mencionado, criticamente, no jornal "A Luta" mecanismos de contrato, que Bilhão (1999, p. 63) descreve na obra chamada "Rivalidades e solidariedades no movimento operário: Porto Alegre, 1906-1911":

[...] Cada operário despedido de qualquer fábrica recebe um dos tais livretos, atestados, ou coisa que o valha e onde vem consignado o motivo por que deixou de trabalhar o operário; por sua vez o patrão, a quem o operário desempregado for pedir trabalho, exigirá a apresentação do atestado [...] (BILHÃO, 1999, p. 63).

Após 1932, quando Getúlio insere as leis trabalhistas em âmbito Nacional com a promoção da Carteira de Trabalho, esta experiência não era completamente desconhecida pelos gaúchos. Sobre o segundo dado aprofundado, em contexto local, Padoin (1992) ressalta que a "consciência de classe" do comércio e da indústria, ou classe patronal, herdada do período da República Velha do Brasil, no RS é acentuada após 1930 pelo Estado Corporativista de Getúlio Vargas.

Entre 1930 e 1932 houve baixo índice de incorporação legal do Estado das classes, tanto patronais quanto proletárias. Contudo, em 1933, através da reformulação da lei sindical que garantia participação em eleições de representantes de classes na constituinte, a adesão começou a se alterar (ARAUJO, 2002). Houve maior resistência da classe patronal ligada as associações comerciais, o que talvez explique o motivo do estado do RS possuir uma única adesão da classe patronal em 1932 (ARAUJO, 2002). Cabe evidenciar que nos estudos de Padoin (1992), a CACISM integrou a classe da indústria em sua representação somente em 1976. Forjaz (1984), aprofunda melhor os ganhos políticos que a classe empresarial passa a ocupar com o Estado Corporativista. Lembrando que o RS após o Estado Novo de Getúlio Vargas é convencionado a ocupar o status de "Celeiro do Brasil". Pelo menos nas regiões de maior concentração urbana do Sudeste, onde o Estado passou a investir, 
a classe Industrial obteve alguns privilégios: o Conselho Federal de Comercio Exterior (CFCE), Conselho Técnico de Economia e Finanças (CTEF) e Conselho Nacional de Política Industrial e Comercial (CNPIC). Estes conselhos intervieram nas relações exteriores com políticas de proteção alfandegária entre outras formas.

No caso brasileiro, as associações de classe são instrumentos cruciais para prática política do empresariado, sendo sua via de comunicação com os poderes públicos, quer via federal, quer regional. Elas permitiram furar o espaço viciado da política partidária, possibilitando uma outra frente de contatos com o Estado (FORJAZ, 1984).

A partir destes elementos cabem algumas reflexões: embora o Estado do RS não tivera muitas organizações de classe patronais legalmente incorporadas pelo Estado Novo, durante este período, ao menos em Santa Maria, a Associação de Classe de Comerciantes (CACISM) começava a se colocar como classe dominante, aliando-se ao processo de centralização industrial no Sudeste. A classe exclusivamente industrial de Santa Maria não se efetivou como organização alinhada ao Estado Federal em razão da centralização política, mas também não se organizou alinhada às circunstâncias econômicas locais. Nesse sentido, Forjaz (1984) ressalta que a burguesia industrial paulista constantemente mantinha laços com os cafeicultores.

Mas se não houve um interesse empresarial de organização de classe industrial em Santa Maria, houve interesse dos empresários comerciantes que possivelmente captavam recursos por diversos órgãos públicos e privados com os mais variados laços e compromissos assumidos com diferentes classes e grupos. O terceiro dado aprofundado está relacionado com o fato que Santa Maria historicamente possui grande contingente de funcionários públicos, embora não houvesse interesse local com o desenvolvimento da indústria, comodamente os investimentos em comércios e serviços sempre pareceram vantajosos. Conforme Padoin (1992), em 1988, Santa Maria possuía mais ou menos 20 mil funcionários públicos ligados ao Exército, Aeronáutica e Brigada Militar; 3600 professores estaduais; 1136 professores municipais; 994 funcionários municipais; 2689 funcionários da Universidade Federal de Santa Maria (UFSM) e 1 mil e 365 professores da UFSM. No ano de 2016, a UFSM contava com 4765 funcionários totais em Santa Maria, sendo que destes, 1669 são professores do ensino superior (WAHLBRINK, 2020). Consta ainda que estão matriculados 20 mil alunos no campus sede (Camobi) e 2183 alunos frequentam aulas no centro de Santa Maria (WAHLBRINK, 2020).

Padoin (1992) ressalta que o perfil do empresariado de Santa Maria é de uma classe ligada ao ramo comercial diversificado, tendo suas origens em antigos e pequenos comerciantes que prosperaram economicamente. A autora ainda chama a atenção para o fato de que os empresários industriais investem em diversos ramos do comércio e em terras, identificado que a classe industrial se confunde 
com a latifundiária (PADOIN, 1992). A autora não traz nenhum dado que corrobora com tal afirmação, mas traz uma fala do antigo presidente da CACISM, Cirilo Costa Beber, no ano de 1990:

O empresário investe onde tem melhor retorno, melhor lucratividade e segurança. Se ele não tem condições de competir, ele se desvia do negócio original. A indústria não desenvolveu-se em Santa Maria porque os empresários nos anos passados, observaram que os rendimentos no comércio eram maiores e mais seguros (PADOIN, 1992, p. 71-72).

Para aprofundarmos o quarto tema, concluímos o terceiro com a reflexão de que Santa Maria não se industrializou de maneira mais definitiva, devido a comodidade dos empresários locais, que permitia optar pelo comércio, tendo o funcionalismo público como demandantes em constante crescimento, mesmo antes do referido "milagre econômico" da década de 1970, durante a ditadura militar no país. Além dos funcionários da Universidade Federal, como também de outras instituições de ensino, fazem parte do núcleo de população assalariado ligado ao funcionalismo público, o alto contingente de militares presentes na cidade, incluindo membros do Exército e Aeronáutica. Para se ter uma noção, segundo o estudo de Machado (2008), entre os anos de 1908 e 1970, foram implantados no município de Santa Maria 13 unidades militares, entre quartéis, a Base Aérea de Santa Maria, campos de instrução, hospital militar, entre outras unidades.

O quarto item de aprofundamento e delimitando o perfil cultural de Santa Maria, remete aqueles três acontecimentos de via única anteriormente mencionado. O primeiro é que a pecuária fora originalmente o grande impulsionador da economia gaúcha, fornecendo a possibilidade de industrialização e que ganhou um grande impulso com a viação férrea. Padoin (1992), destaca que em 1922 a produção bovina de exportação para outras regiões do país era de cerca de 120.000 e suína de 50.000 . Também o RS exportava cerca de 200.000 litros de vinho e uma série de outros produtos agrícolas e de agroindústria. Padoin (1992) apresenta um gráfico de Argemiro Brum, onde aparece os dados da participação dos Estados do produto industrial do país. De forma resumida, em 1907 São Paulo contribuía com 16,5\%; Rio de Janeiro com 31,1\% e Rio Grande do Sul com 14,9\%. Já em 1938, período correspondente ao Estado Novo de Getúlio, São Paulo contava com uma participação de 43,2\%; Rio de Janeiro com 14,2 \% e Rio Grande do Sul com 10,7\%. Em 1980 o RS contribuía com apenas 5,5 \% enquanto São Paulo com $60 \%$.

Em resumo, conforme a leitura de Padoin (1992), enquanto a elite industrial de São Paulo ganhava espaço político no país, em 1940, as estradas de ferro começam a perder espaço para as estradas de rodagem que recebiam os investimentos que outrora eram enviados às linhas férreas. Lembrando que é neste período que as estradas de ferro passam para a administração Federal. No entanto, as estradas de ferro continuaram desempenhando sua função por muitos anos e seu sucateamento definitivo foi após o governo Fernando Henrique Cardoso (SILVA, 2014). 
Portanto o argumento da perda de importância das linhas férreas não sustenta a explicação. Quanto a pecuária bovina, a autora salienta que com a perda de preços da produção cafeeira, São Paulo e outros estados passam a competir com a produção de gado gaúcha. Importante ressaltar que o gado e o café possuíam preços que oscilavam, e na perspectiva do mercado global, mais a expansão da indústria brasileira que poderia ser beneficiada por estas produções a longo prazo fazem destes motivos insustentáveis para a industrialização não ter obtido maior destaque em Santa Maria.

A CACISM resume ou permeia todos os tipos e grupos do empresariado local. Do mesmo modo, a elite industrial paulista fazia parte da hegemonia do Estado Corporativista. Sendo assim, a própria expansão da indústria paulista pela intervenção do Estado contribuiu para desindustrialização de Santa Maria, por causa de uma certa vantagem de concorrência. Da mesma forma, a CACISM emergiu como nova hegemonia em um contexto diferente e ocupou totalmente o espaço deixado vago por outras possibilidades econômicas, tendo uma cômoda vantagem de possuir em Santa Maria uma larga demanda de consumidores formada por funcionários públicos. Isso se alinha a fala de Cirilo Costa Beber, citada anteriormente.

\section{A PAISAGEM CULTURAL EM SANTA MARIA E AS RELAÇÕES SOCIOECONÔMICAS}

Segundo Nogueira (2011), diversas movimentações e escolas variadas como Bauhaus (Alemanha) e Le Corbuisier (França) influenciaram a arquitetura moderna brasileira. O movimento caracterizou-se por ser multifacetado. Um ano após a Semana de Arte Moderna no Brasil em 1922, Gregori Warchauvchik, arquiteto russo formado na Itália, chega ao Brasil em meio ao contexto de afirmação do Nacionalismo. É neste meio que ele encontra território favorável para aplicar o que havia visto e estudado na Europa (NOGUEIRA, 2011). Ainda segundo a autora, as propostas de Warchauvchik e as propostas sugeridas pela Arquitetura Internacional passam a ser questionadas para dar lugar a uma arquitetura que pudesse na prática estar adequada as características culturais do Brasil. Espelhando-se neste movimento de São Paulo e Rio de Janeiro, a cidade de Porto alegre, como também Santa Maria, passam a modificar seu contexto urbano, embora Santa Maria se espelhasse mais na capital gaúcha que já possuía arquitetura muito própria (NOGUEIRA, 2011).

Cabe ressaltar nessa análise e, de acordo com Nogueira (2011), se situa no contexto da ditadura do Estado Novo do Brasil, é o início das arquiteturas modernas brasileiras, que segundo a autora, se inicia expressivamente a partir do ano de 1935 com Lúcio Costa, Afonso Leão, e especificamente em Santa Maria, com a grande expressividade das obras de Luiz Arthur Vallandro. Algumas obras são tratadas no estudo de Nogueira (2011), e apontadas em nossa análise, mas no sentido simbólico e cultural, como a arquitetura da Universidade Federal de Santa Maria, conforme a Figura 1. 
Figura 1 - Antiga Reitoria da Universidade Federal de Santa Maria.

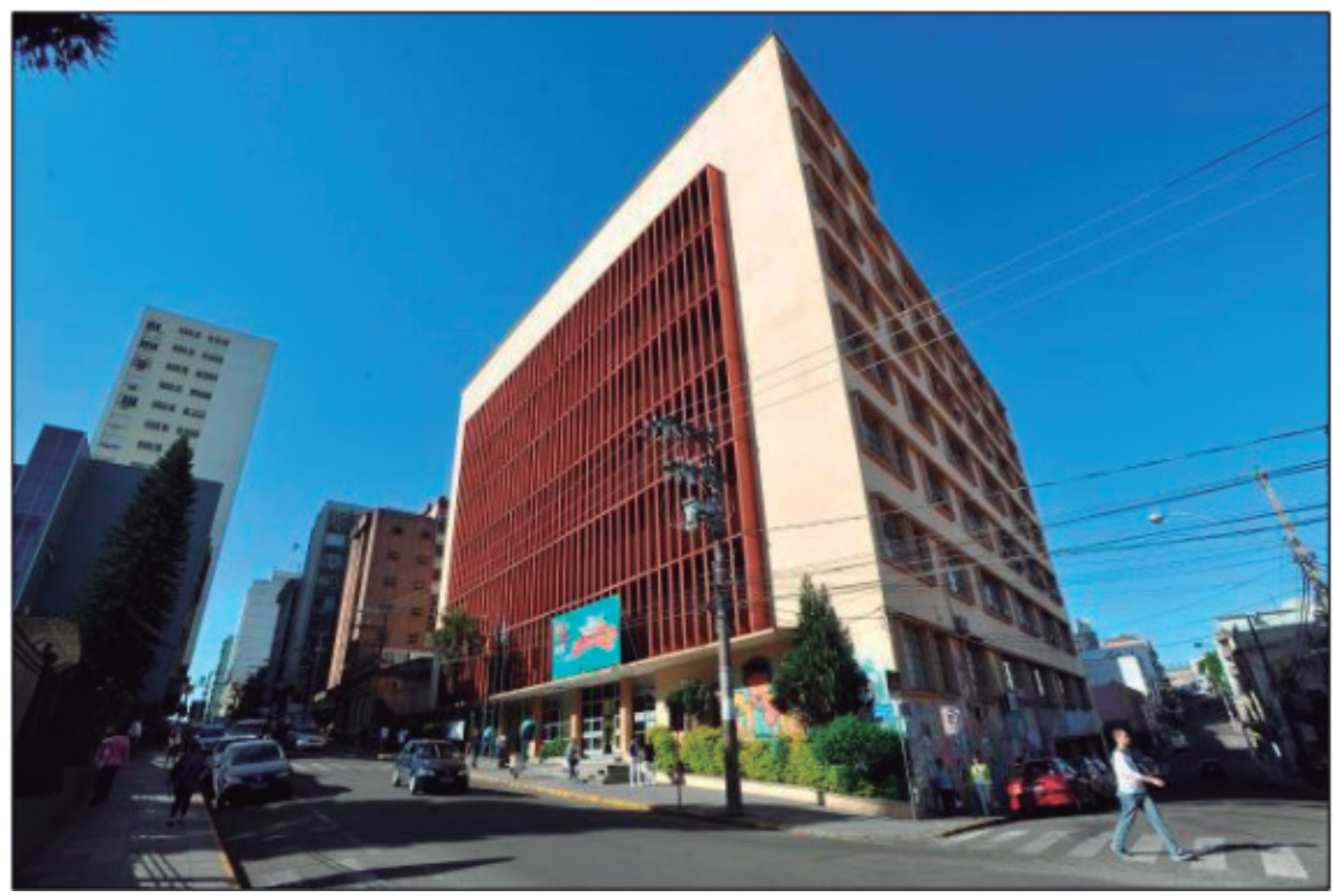

Fonte: Diário de Santa Maria, 2014.

Já a Figura 2, marca o desenvolvimento até aqui, e é um signo, um registro e uma marca que representa a materialidade histórica da ascensão política, econômica e cultural da hegemonia atual que é a relação entre CACISM e funcionalismo público de Santa Maria. Assim como toda a aparência moderna de Santa Maria, e desta forma, a arquitetura moderna na paisagem suprime aos poucos o que era anterior a ela, conforme a Figura 3.

Figura 2 - Centro de Santa Maria visto do Monumento ao Ferroviário no inverno de 1999.

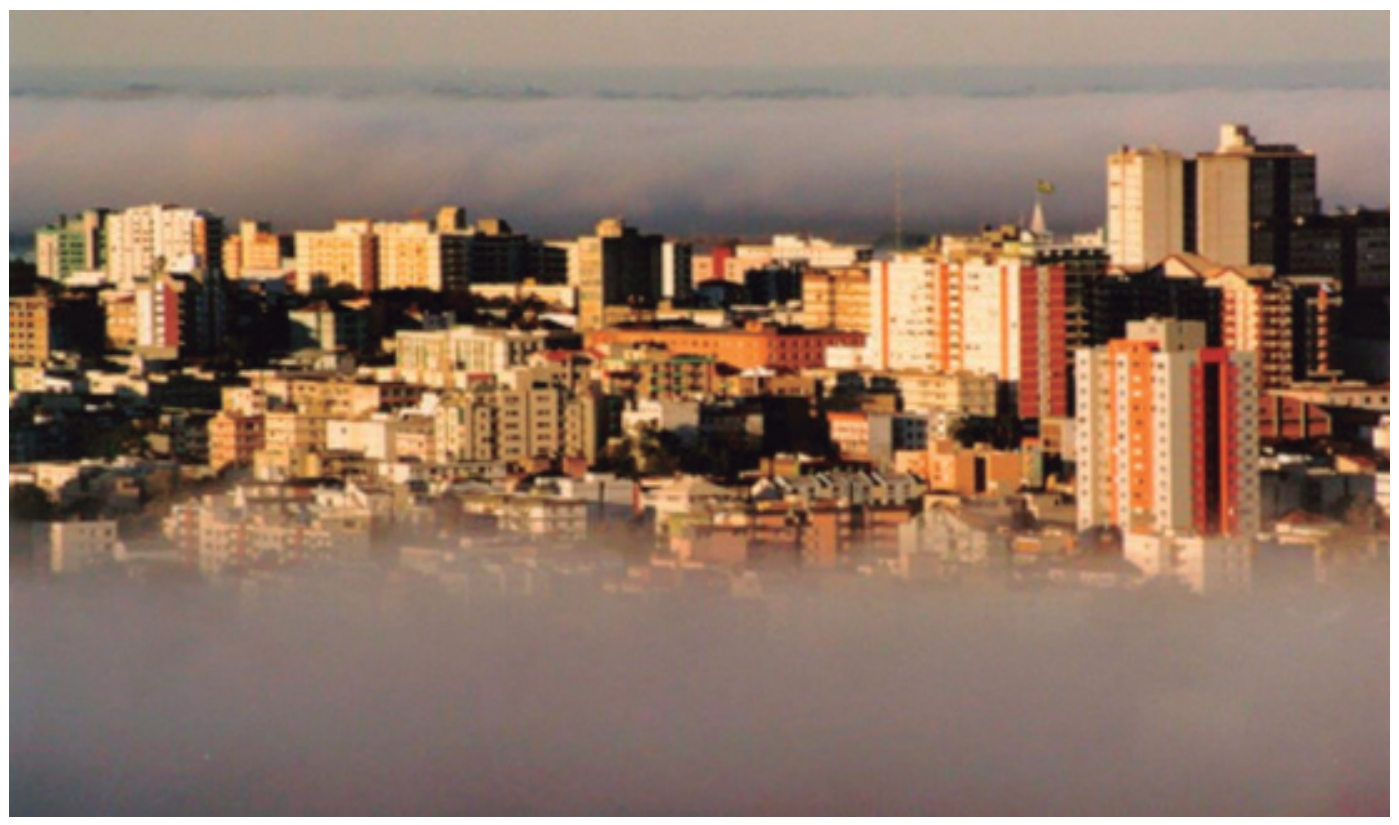

Fonte: Google Imagens/Panoramio, 2013. 
Figura 3 - Esquina das ruas Coronel Niederauer e Serafim Valando, no Bairro Centro, Santa Maria, RS.

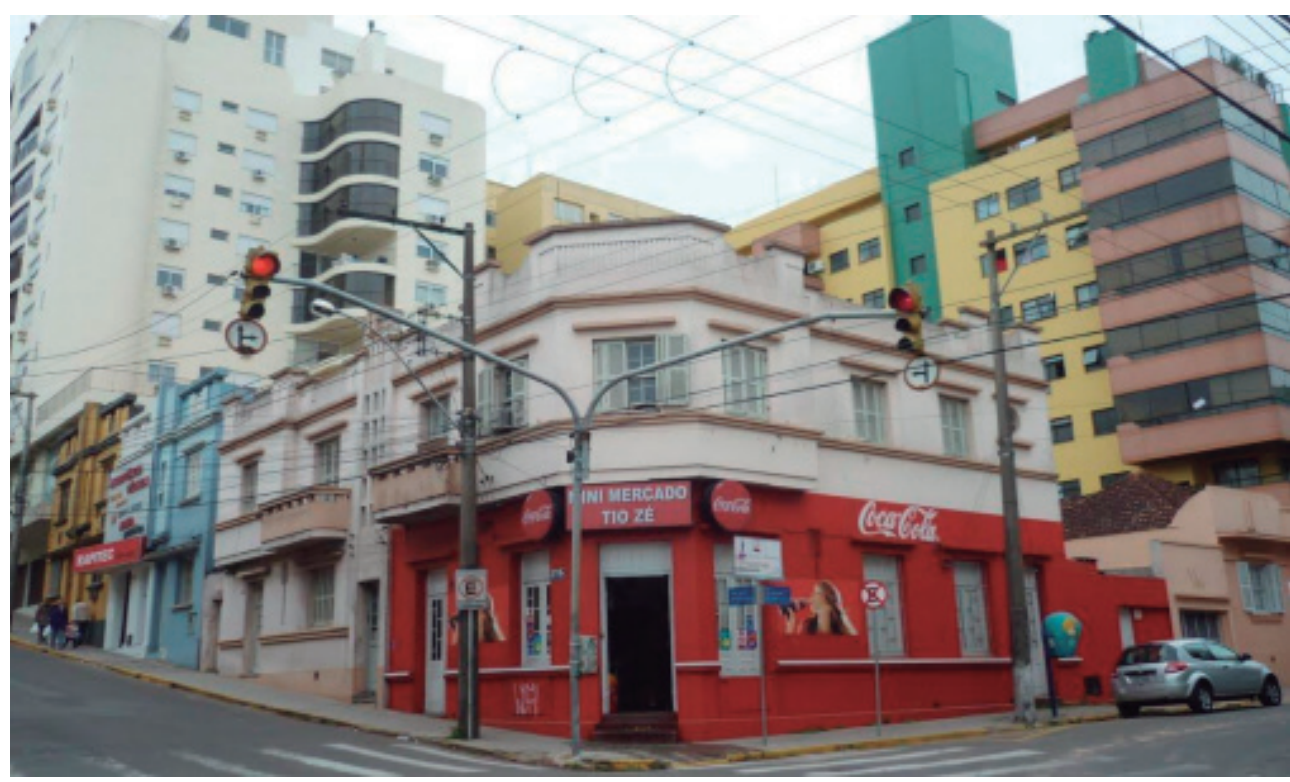

Fonte: acervo particular dos autores, 2016.

Conforme Silva (2014), em 1897 uma empresa belga chamada de Compagnie Auxiliare de Chemins de Fér au Brésil havia arrendado da EF Porto Alegre/Uruguaina. Em poucos anos Santa Maria ganhava destaque como um importante centro ferroviário e em 1900 passou a comandar o tráfego de trens no Rio Grande do Sul. Em 1907 foi inaugurado em Santa Maria a Vila Belga, projetada pelo engenheiro belga Gustave Vauthier, funcionário da concessionária que administrava as linhas férreas. Segundo Nogueira (2011), Vauthier teria se inspirado no Tratado de Arquitetura proposto pelo belga Louis Cloquet, este tratado indica que, por exemplo, os bairros construídos deveriam ser próximos ao centro para que se evitasse segregação, isolamento e hostilidades. Havia um cuidado para que todas as residências fossem construídas de modo que recebessem ventilação e iluminação natural por igual. As arquiteturas eram diferenciadas de modo que se preservassem a individualidade e especificidade de cada família. As casas na Vila Belga, juntamente com Gare, o prédio administrativo, depósitos, anexos e largo da estação férrea e seu muro de pedras, a sede de edificações de apoio da Cooperativas de funcionários da viação (COOPFER), e a Escola Estadual Manoel Ribas - antiga Escola Santa Terezinha, formam a denominada mancha ferroviária de Santa Maria (SILVA, 2014).

Desse modo, as formas históricas, materializadas na paisagem de Santa Maria, são marcas de determinados períodos históricos, do Brasil e do Rio Grande do Sul, que associados as características próprias do desenvolvimento social e econômico local, aparecem como registros da construção socioespacial do munícipio. São marcas e signos de períodos de industrialização, 
quando Santa Maria era considerado um dos principais entrepostos ferroviários do estado do RS, e também refletem a derrocada do processo industrial da cidade, cujo aparato industrial, em tempos atuais, tornaram-se rugosidades na paisagem, como coloca Degrandi (2012) ${ }^{8}$, e também espaços de pobreza e privação social (SPODE, 2020).

Silva (2014) ainda inclui outros estabelecimentos que refletem a história materializada de tempos remotos em Santa Maria, como a antiga Escola de Artes e Ofícios, onde hoje está instalado o hipermercado Carrefour, conforme a Figura 4, o Colégio Estadual de Manoel Ribas (Figura 5) e a Gare da Estação Férrea (Figura 6). O processo político e econômico molda o espaço e de acordo com cada tempo histórico ele transforma o significado dos objetos presentes no espaço, como pode ser identificado no edifício do Hipermercado Carrefour.

Figura 4 - Hipermercado Carrefour - Antiga Escola de Artes e Ofícios.

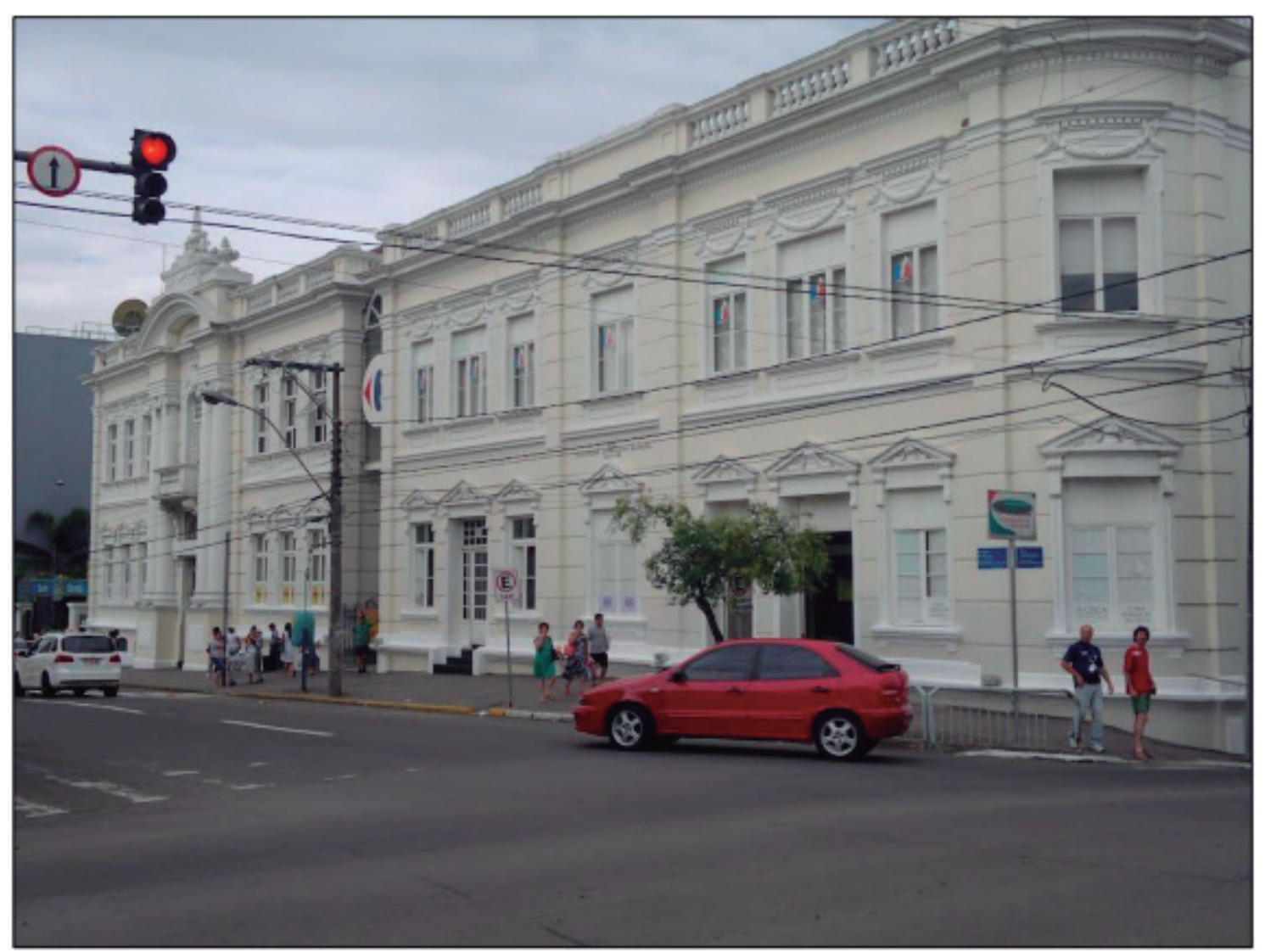

Fonte: Google Imagens/Panoramio, 2015.

\footnotetext{
${ }^{8}$ Degrandi (2012) divide os usos históricos do território em Santa Maria em uso militar, uso ferroviário, uso corporativo e uso universitário, identificando o uso ferroviário, atualmente, como rugosidade na paisagem do município, de acordo com o conceito delineado por Milton Santos. Para o conceito de rugosidades ver: SANTOS, M. A natureza do espaço. Técnica, tempo, razão e emoção. 4. ed. 2. reimpr. - São Paulo: Editora da Universidade de São Paulo, 2006.
} 
Figura 5 - Colégio Estadual Manoel Ribas.

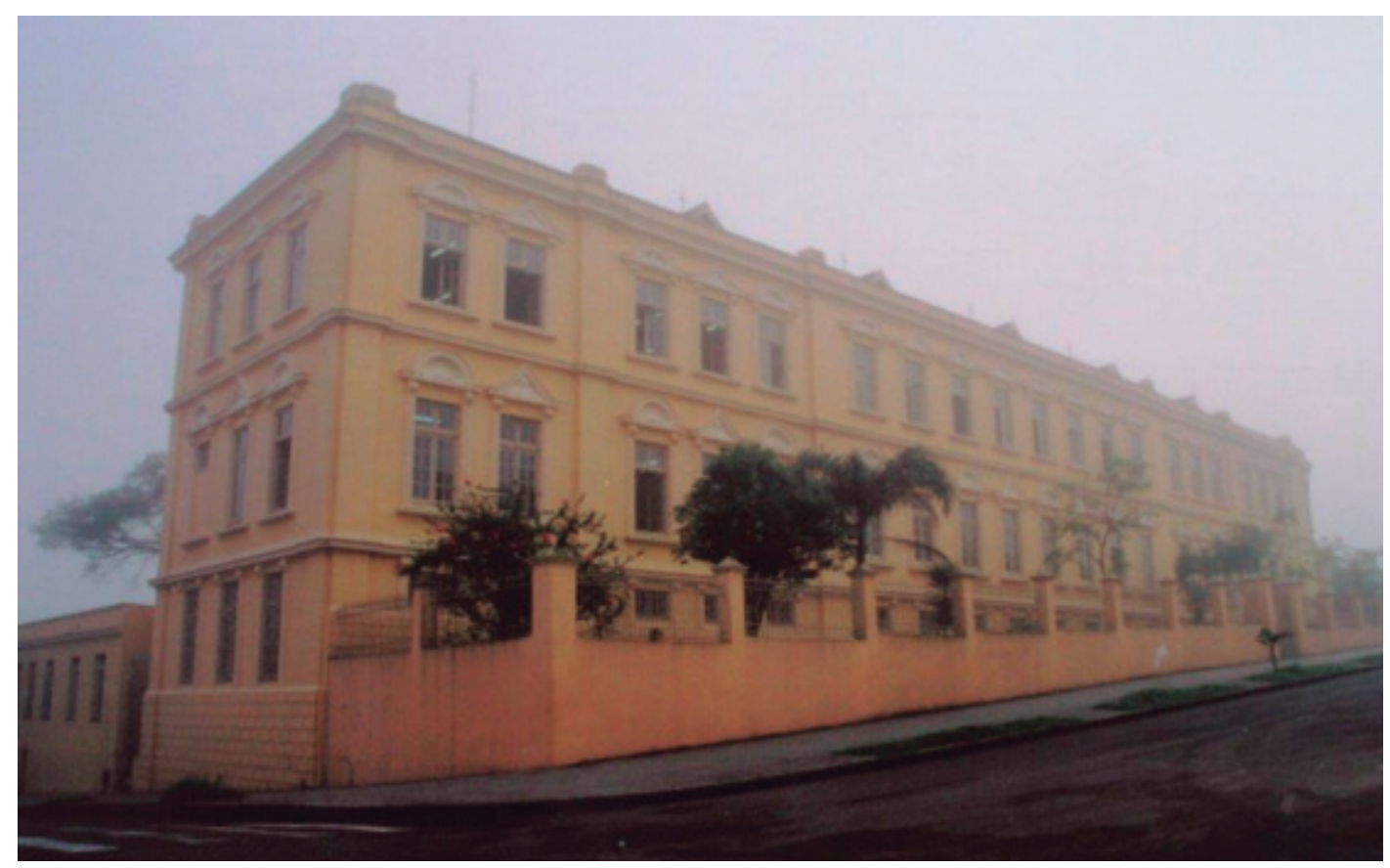

Fonte: Geoview, s/d.

Figura 6 - Estação Férrea de Santa Maria.

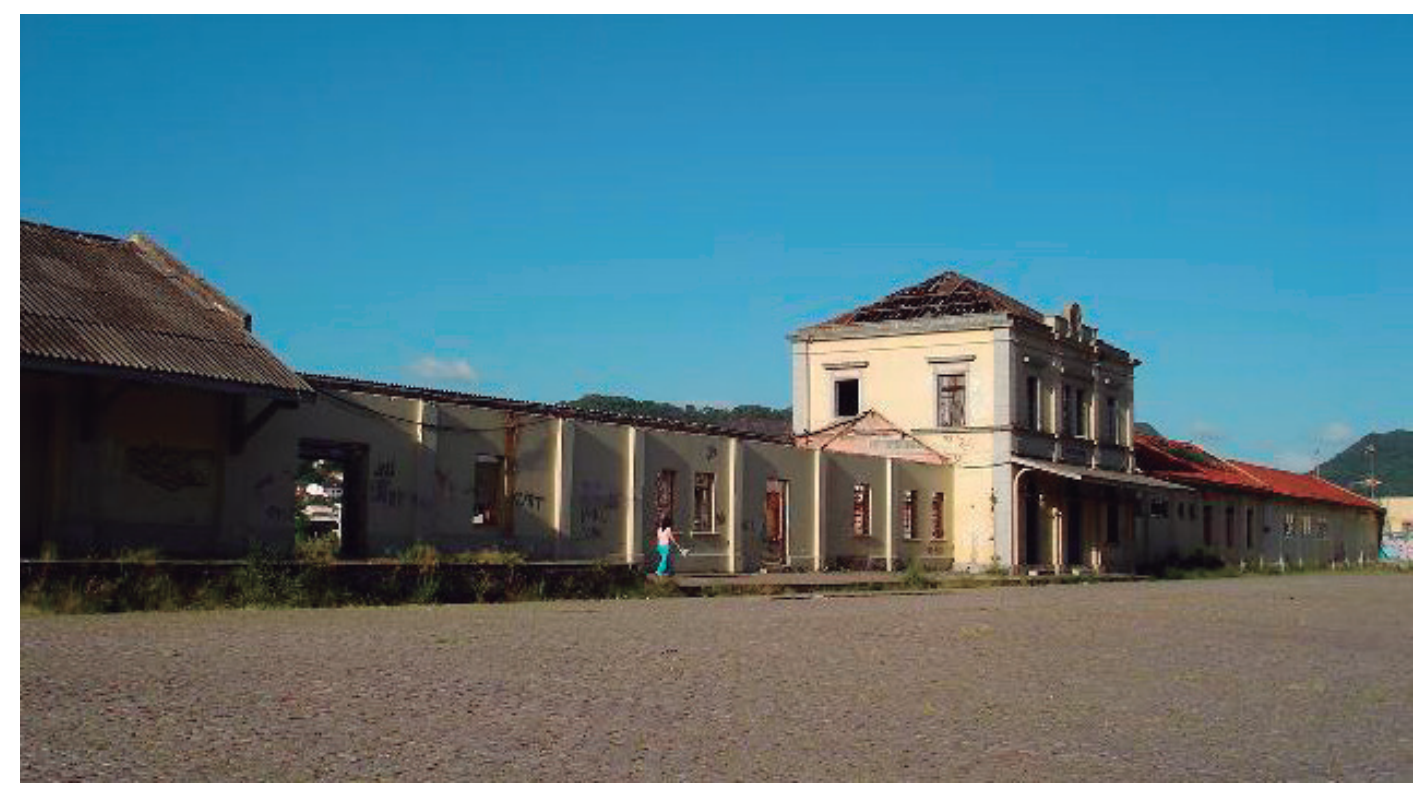

Fonte: Assis Brasil, s/d.

Todas estas arquiteturas, formas construídas, relacionadas ao período histórico da República Velha, simbolizam um registro histórico, que pouco a pouco vem sendo esquecido, que é o significado de os primórdios da industrialização do Brasil, do Rio Grande do Sul e de Santa Maria, movidas, indutivamente, pelas estradas de ferro e palas vastas organizações de classe. Significam, também, o federalismo, por sua vez a descentralização e o ensaio de um Estado Liberal que se encontra perdido. 
Significados de pouca compreensão, pois não se concebe a partir das relações atuais, que foram perdidas por um Estado Corporativista, centralizado e que fez de Santa Maria uma ilha moderna em meio a imensidão agrária do "Celeiro do Brasil".

\section{CONSIDERAÇÕES FINAIS}

Santa Maria, como demostrado ao longo do texto, mostra-se uma cidade cosmopolita, uma mescla de culturas, arquiteturas, dimensões e matrizes econômicas, principalmente, com raízes ferroviárias, militares, educacionais e voltadas à saúde. Neste ínterim, a cidade é constituída de uma multiplicidade de paisagens culturais e patrimônios que rememoram seu passado e fazem compreender a contemporaneidade de suas rugosidades.

A cidade é uma linguagem viva a ser decodificada e entendida, a ser esmiuçada e para isso, as bases culturais, econômicas, sociais, entre outras, precisam ser descritas, interpretadas, entendidas em essências e em temporalidade. Os pontos mencionados, como a Antiga Reitoria, a Gare da Estação Férrea, o Monumento ao Ferroviário, a Escola de Artes e Ofícios e o Colégio Manuel Ribas são marcas históricas do processo de formação de Santa Maria.

Através do exposto, percebemos de forma contundente que Santa Maria possui um vínculo com a ferrovia, pois tem um grande destaque para o desenvolvimento da referida cidade. Além de aumentar a população residente, promoveu um incremento comercial próximo a Gare, organizando assim o espaço em seu entorno baseada em atividades da rede ferroviária, como armazéns e pousadas. Também, a região localizada próxima a estação de Santa Maria faz parte do centro histórico e cultural do município, onde engloba a Avenida Rio Branco, tendo bastante destaque desde o período que se iniciou a instalação das primeiras aglomerações. Ainda possui o patrimônio tombado pelo Instituto do Patrimônio Histórico e Artístico do Estado (IPHAE), onde os imóveis situados nessa região são preservados, incluindo a Vila Belga e a Gare.

Investigar suas materializações, bem como defender sua preservação, é uma forma de manter viva a memória e a historicidade urbana. Essas materializações, também, possibilitam relacionar os acontecimentos de outrora com a caracterização urbana atual, pois os monumentos mencionados estão, em sua maioria, em áreas centrais da cidade.

Concluímos, assim, que a Geografia Cultural e a discussão de patrimônio são fundamentais ao entendimento da estrutura socioeconômica atual santa-mariense, pois remontam a trajetória do urbano e permitem entender em detalhes as suas quatro fases de desenvolvimento, porém com um olhar que vai além da técnica e da quantificação, mas que potencializa a memória coletiva e a interpretação dos signos postos na paisagem por meio da afetividade e do sentimento de pertença. 


\section{AGRADECIMENTOS}

O presente trabalho foi realizado com apoio da Coordenação de Aperfeiçoamento de Pessoal de Nível Superior - Brasil (CAPES) - Código de Financiamento 001 e Programa Nacional de Pós-doutorado (PNPD).

\section{REFERÊNCIAS}

ARAÚJO, A. M. C; JÚNIOR, A. B. Do corporativismo ao neoliberalismo: Estado e trabalhadores no Brasil e na Inglaterra. Boitempo, 2002.

ASSISBRASIL. Santa Maria - Fotografia da Estação Férrea. Disponível em: http://assisbrasil.org/ joao/santamaria.htm. Acesso em: 15 de dezembro de 2016.

BEBER, C. C. Santa Maria 200 anos: história da economia do município / Cirilo Costa Beber. - Santa Maria: Pallotti, 1998.

BILHÃO, I. Rivalidades e solidariedades no movimento operário: Porto Alegre, 1906-1911. (Vol. 30). EDIPUCRS. Porto Alegre. 1999.

CLAVAL, P. “A volta do cultural” na Geografia. Mercator - Revista de Geografia da UFC, ano 01, número 01, 2002.

COSGROVE, D. A geografia está em toda parte: cultura e simbolismo nas paisagens humanas. Paisagem, tempo e cultura. Rio de Janeiro: EdUERJ, p. 92-123, 1998.

DEGRANDI, J. O. Verticalidades e horizontalidades nos usos do território de Santa Maria-RS. Programa de Pós-Graduação em Desenvolvimento Regional. UNISC. Tese de Doutorado, Universidade de Santa Cruz do Sul, 2012.

DIÁRIO DE SANTA MARIA. Endereços de locais de prova do Enem em Santa Maria estão errados no cartão do estudante, 2014. Disponível em: https://bit.ly/354zmPn. Acesso em: 10 de dezembro de 2016

FIGUEIREDO, L. C. Perspectivas do Patrimônio Cultural: algumas reflexões. Geografia Ensino \& Pesquisa, v. 17, p. 55-69, 2013. 
FORJAZ, M. C. S. Industrialização, estado e sociedade no Brasil (1930-1945). In: Revista de Administração de Empresas, v. 24, n. 3, p. 35-46, 1984.

GEOVIEW. Colégio Estadual Manuel Ribas. Disponível em: https://assisbrasil.org/joao/santamaria.htm. Acesso em: 15 de dezembro de 2016.

MACHADO, M. K. A presença do exército e da aeronáutica na organização espacial de Santa Maria-RS. Dissertação (Mestrado). Programa de Pós-Graduação em Geografia e Geociências. Centro de Ciências Naturais e Exatas, Departamento de Geociências. 2008.

NOGUEIRA, A. P. O patrimônio arquitetônico moderno de Santa Maria: as casas do arquiteto Luiz Arthur Vallandro - Um resgate analítico. (Santa Maria/RS), 2011.

PADOIN, M. M. O empresário comercial em Santa Maria/RS (uma análise histórica sobre a CACISM). Dissertação (Mestrado em História) - Universidade Federal do Paraná, Curitiba. 98f. 1992.

PETERSEN, S.; LUCAS, M. E. Antologia do movimento operário gaúcho. Porto Alegre: EdUFRGS, 1992.

SANTOS, M. A natureza do espaço. Técnica, tempo, razão e emoção. /Milton Santos. 4. ed. 2. reimpr. São Paulo: Editora da Universidade de São Paulo, 2006.

SILVA, A. C. da. A ferrovia, o patrimônio e a Vila Belga (Santa Maria/RS). Trabalho de Graduação Universidade Federal do Rio Grande do Sul. Instituto de Filosofia e Ciências Humanas. Curso de História: Bacharelado, RS, 2014.

SPODE, P. L. C. Pobreza e privação social na área urbana de Santa Maria, Rio Grande do Sul: uma análise a partir dos usos do território. Dissertação (mestrado) - Universidade Federal de Santa Maria, Centro de Ciências Naturais e Exatas, Programa de Pós-Graduação em Geografia e Geociências, RS, 2020.

WAHLBRINK, A. Socialização e desempenho acadêmico dos alunos moradores da casa do estudante universitário - CEU II da UFSM, de Santa Maria, RS. Trabalho de Graduação - Universidade Federal de Santa Maria, Centro de Ciências Sociais e Humanas, Departamento de Ciências Sociais, Curso de Ciências Sociais Bacharelado. 2018. 